\title{
Implication of freedom and change in Nigeria's women education programme: Is autonomy necessary?
}

\author{
Benedicta Ehi Momodu \\ Department of Educational Foundations, Federal College of Education, Asaba, Nigeria \\ Phone No. 08037645095 \\ E-mail address: benemomodu@gmail.com
}

\begin{abstract}
The clamour for equal treatment and opportunity has made women desirous in their struggle to break the shackles of cultural imperative, which they believe have enslaved them. Social indicators reveal that women deserve equal opportunity with their male counterparts. The trend of women education and the current of socialization among social crusaders, gender practitioners and women showed freedom as both a cherished goal and threat to the girl-child. Can freedom therefore be something essential in women education and socialization? Put differently, can the nourishing of the tendency towards autonomous activities in a "proper" social environment not bring about the inherent freedom and the noblest image of the girl-child? In an attempt to provide answers to this questions and other issues, the a priori-deductive method of analysis was employed in examining autonomy, human aspect of freedom, women education, and socialization. It was emphasized that to enjoy freedom without some degree of autonomy is gross abuse of freedom. The inherent freedom is realizable only if women education is refocused towards encouraging independence, self-knowledge, and rational choice.
\end{abstract}

Keywords: Autonomy; Freedom; Change; Girl-Child and Women Education

\section{INTRODUCTION}

The clamour for equal treatment and opportunity has made women desirous in their struggle to break the shackles of nature, culture and men's authority, which they believe have been used to enslave them in the past and still been employed even in present to do same. Social indicators reveal that women deserve equal opportunity with their male counterparts. The trend in girl-child or women education and the current of socialization among social crusaders, gender practitioners and women showed that freedom is both a cherished goal and a threat to women (Miller, 1974). Freedom and change are natural issues which everyone long to have. However, in most societies, freedom and change can either be restricted or be in favour of the individual longing for them. In other words, even though freedom and change are natural propensities, it is society that determines the extent of freedom and change an agent enjoys.

This means that if society allows relative freedom, there would not be a situation where the strong imposes arbitrary constraints on the weak. In that case, the girl-child or woman is 
protected by law, fellow men and society. It is on this ground, this author examines the possibility of refocusing women education so that women, including the girl-child, can be independent-minded. This is to realize the fourth quality of instruction in the National Policy on Education: the acquisition of appropriate skills, ability and competence in mental and physical equipment for the individual to live and contribute to the development of society (FRN, 2004).

What this means is that the desire for freedom and change is possible, if and only if, such quest is seen beyond theoretical epistemology, abstraction and academic exercise to the extent of actually concretizing the girl-child education in Nigeria. It is when recipients of an education system make use of knowledge, experience and skills acquired in other areas of life that education becomes meaningful and realistic.

In doing this, this study employed the a priori-deductive technique of philosophical analysis method in examining the issue of autonomy, human aspect of freedom, women education, socialization, and the attempt to answer the question: can the noblest image of women be realizable by the quest for freedom and change? This study is significant because its findings will help in refocusing the present trend of women for change initiative, and women education generally in the country.

\section{CONCEPTUAL FRAMEWORK}

The man, who is truly free, is the man who is in control of his passions. What this implies is that if a man is free he must also be free in his "will" or true "self". For agency to be free, they must be relatively autonomous in their thoughts and conducts in certain important areas of their lives. Is it possible for man to put the passions under control? Alternatively put, is the girl-child capable of putting something that is part of her constitution under control without exhibiting it sometimes?

The rationalists argue from the angle of positive freedom that such freedom is a dangerous extension of nature, that freedom should have proper application only in a social context. In other words, there is no absolute freedom. The belief that man is free, in the popular mind, does not mean that man is free in the practical sense. Freedom only exists in human thought. Plato and other rationalists believe that man is a rational-thinking being therefore he is capable of putting his emotions under check. Unlike the rationalists, the existentialists believe that it is the passions that controls man's rationality. This argument gives us the opportunity to understand that man is endowed with reason and the passions. Which means man is a rational-emotional being.

Nature and social constraints obstruct and deflect the real will from its course. Freedom has its natural constraint; it could be oppressive and subtle in nature. Locke (1948) speaks plainly, when he proclaims that "the greatest evil of all was to be subjected to the inconstant, uncertain, unknown arbitrary will of another man. It is this arbitrary subjection of women to indecent status that women do not want. They recognize and understand too that their male counterpart is subjective, irrational and inconsistent in their approach to things, events, objects, and phenomena. It therefore follows that culture is not justified in its social subjugation of the girl-child to the role of second-class citizen.

Autonomy is allowing the girl-child and women the freedom to express their interest in areas their potentials can be actualized. To be free means there are no constraints on people in doing things where their potentials lie. Peters (1964) also argues that freedom is justified on the ground that it promotes the woman's interest and maximize her opportunity for doing 
what is worthwhile. In other words, if women have the right opportunity in a favourable environment, there is the tendency for them to realize their potentials and putting them to use.

\section{CLARIFICATION OF CONCEPTS}

\section{(a) Education}

In a wider context, education performs two basic functions in society. Namely, to conserve and transmit useful, practical, cognitive skills and knowledge along with the cultural heritage learners' receive from one generation to the next generation. And the other function is to simultaneously enable a positive critique of their heritage so as to provide, and create, a more adequate response for further changes. Both dimensions of education are to make learners creative and critical of learning. Education therefore is a means to an end or desired goal and the future of a nation depends on the education of a younger generation who are responsible, thoughtful, and democratic individual citizens (Ibrahim, 2002).

In pre-colonial and colonial eras in Nigeria, education was almost reserved for the boy child. It was very rare for parents to educate the girl-child because going to school may delay her getting married and giving birth to children. Nevertheless, as the wind of feminism began to blow in postcolonial Nigeria, those who were opportune to have Western education understand its benefits and they encourage parents to send the girl-child to school. Today there is influx of the girl-child at all levels of the educational system, even though the desired target is yet to be achieved.

The issue of autonomy in women education is about freedom and its relationship to women, as expressed in variety of ways. Education is liberating and not excluding, not relegating, nor marginalizing. The idea of freedom is not just a product, but part of the process of education, which is meant to remove the girl-child from perpetual darkness or ignorance, and to free the mind from errors, dogma, stereotype, assumption and presupposition that come with existence.

\section{(b) Autonomy}

What exactly is autonomy? It generally means "self rule". It was originally applied to emerging independent city-states in ancient Greece. The notion of autonomous individual and idea of independent freethinking being become for some a human excellence. This was why progressivists argue that learners' thinking has to be respected, allowing them to see the point of what they are imbibing, so that they can be free to pursue their own conceptions in their own liberal ways. Because independence aids firsthand learning through experience and active problem solving strategy, and taking responsibility for one's thought, action and conduct.

Dearden (1972) sees autonomy as what will develop a lively critical faculty, free of prejudices and obfuscating abstraction. Thus, people are autonomous to the degree that what they think and do in important area of their lives, cannot be explained without reference to their own activity of mind. That is to say, the explanation of why they think and act as they do in these areas must include a reference of their own choice, deliberating, reflecting, judging, deciding, planning and reasoning.

The point here is that choosing, deliberating, contemplating, deciding and so on are conscious, autonomous activities that express sense of freedom in human action and conduct. In other words, autonomy is an expression of the human mind, and it manifests in the knowledge, awareness and experience an agency possesses. 


\section{(c) Freedom and Predicaments of the Girl-Child in an Authoritarian Environment}

There are two main components of freedom. These are the notions of possible wants and the absence of social constraints upon these wants. The girl-child's possible wants could be taken for granted. However, freedom may arise when there is a possible constraint on wants. For instance, there are situations in which certain constraints are imposed on womens' wants. When there is financial problem in the home, the girl-child is compelled to drop out of school to allow male children in the family to continue with their education until there is sufficient money to send the girl-child to school. In most cases, the girl-child may never continue with formal schooling. Since culture and nature have limited her biological period of child rearing age, they are then given out in marriage. From this point of view of freedom, there is no justice, fairness and equity.

Secondly, some cultures and traditions in the Nigerian environment are very intimidating, segregating and discriminating against the female folk. The practice of widowhood in African experience favours men more than women who are bereaved of their husband. They are made to pass through all kinds of dehumanizing conditions to prove their innocence as par the cause of death of their husband. However, if the woman dies the man is not made to pass through any form of treatment.

Thirdly, on circumcision, women are forced to go through severe pains to deter them from sexual promiscuity. In other words, women have no right to enjoy their feelings of being a woman or womanhood. It is men who ought to derive pleasure from the act of conjugal bliss, which both of them are meant to accomplish. Culture makes men to believe that by paying a woman's bride prize, they have bought her over as property to be used and dumped. Culture also allows men to cheat on their women.

All kinds of excuse are provided to deter women from extra marital sex. The woman comes to believe those excuses as true knowledge, which she does not only adhere to, but passes on to her daughters who also pass them on to subsequent generations. It is wrong for women to question the legitimacy of their husbands' action, for seeking extra-marital gratification outside the home. In trafficking and prostitution, the girl-child yields better income than her male counterpart. The girl-child is more exposed to all forms of sexually transmitted infections and untold hardship.

\section{(d) Women Education}

The Beijing Declaration Document of the twenty-third Assembly states that women education, including the girl-child, is a human right and an essential element for the full enjoyment of all other social, political, economic and cultural rights that are available (Women Watch, 2005). This Document and other related documents laid emphasis on the importance of promoting gender equality, women empowerment and campaign to persuade member countries to focus on the education of women, which have yielded little or any positive result in the Nigerian state. Women education programme is aimed at assisting women to function effectively in the social, political, economic, and cultural sphere of life. This does not mean that women do not possess these traits, rather they are vehicles of creating awareness on and developing high self-esteem in women. As well as being efficient in their dealings ranging from proper management of the home, offices and environment (Jike, 2001). It also helps women to be intellectually sound, rationally disposed, and patriotic so that they can contribute meaningfully and realistically to national development. 


\section{IS THE QUEST FOR FREEDOM AND CHANGE NECESSARY IN WOMEN EDUCATION?}

The quest for freedom and change in women education is both a myth and reality. It is a myth in the sense that freedom and change are operational in the human mind, and they are relative terms which connote human being and society. If freedom and change imply human society, it follows therefore that they are determine by humans and society. They determine the amount of freedom and change allowed at a given time. On the grounds of reality, freedom and change are human dispositions and they are inevitable in women education. In other words, freedom and change are both tendencies in man. Freedom is a conscious activity, which a person expresses without seeking for permission in order to excise it. Yet, as a rule-following and self-determined being, learners realize to a reasonable extent, that they can only be free when they are responsive and responsible for their thoughts, conducts and actions in relation to other being-in-the-world. Because freedom presupposes that where our action ends other persons' action continue from there.

And this is where self-control, a measure of rationality, comes in when seeking for autonomy through the girl-child education, which is aimed at freeing their thought and conduct from errors so that they can be capable of making rational decision. Education develops in them respect for reasoning and evidence, together with the capacity to employ rational thought and sound argument to explore their world. Furthermore, the disposition to ask for substantive evidence for their relegation, and to seek for justifiable belief base on relevant evidence are now necessary in women education. They also need knowledge, experience and understanding that are relevant for future purposes. Either by chance or construct, a section of the society cannot impose its will on the generality of the people without disrupting the balance of society. It is a belief in the popular mind that if women are given relative freedom, there is the tendency for them to misuse it because women are cosmetic in their ways. There is also the belief that women do not need freedom and change beyond the home setting. This is not true because experience has shown that man and woman depend on each other's experiences to achieve something great in their homes and society.

\section{CONCLUSION}

Encouraging autonomy in the girl-child or women education is to provide them with awareness, knowledge, experience and understanding that will free their mind from errors so that the pursuit of knowledge will promote self-knowledge, independent-mindedness and rational choice. 


\section{RECOMMENDATIONS}

It was therefore recommended that the girl-child need to learn that there is no freedom without constraints. Rather than engage more in the act of freedom, it should be more encouraging to aspire for a higher level of becoming an autonomous being with earned status (Ireyefoju, 2014).

It is imperative to vigorously enforce the rule of law so that the right of women including the girl-child can be protected. There is also the need for enlightenment programmes that will sensitize women about her role, status and place in society.

Allowing women to take up responsive roles in politics and social institutions will inspire the girl-child to consciously aspires to greater height.

\section{References}

[1] Dearden, R. F. (1972). Autonomy and education. In R. Dearden, P. Hirst and R.S. Peters (Eds). Education and the Development of Reason. London: Routledge and Kegan Paul.

[2] Federal Republic of Nigeria, (2004). National Policy on Education. Lagos: NERC Press

[3] Ibrahim, A. J. (2002). The Nigerian national EFA forum: Facilitating consultation and participation in the realization of EFA Goals. In ed. P. J. Charles and S. N. Iheme (eds). Nigeria Private Sector and Education for All: A Report on the Private Sector Round Table.

[4] Jike, V. T., Social Studies Quarterly 4 (2001) 21-27.

[5] Locke, J. (1948). The Second Treaties on Civil Government ed. Gough. J. Oxford Blackwell.

[6] Miller, J. S. (1974). Essay on Liberty: London Routledge.

[7] Peters, R. S. (1964). Ethics and Education. London: George Allen and Unwin.

[8] Women Watch, (2005). Information and Resources on Gender Equality and Empowerment of Women: Education and Training of the Girl Child Sponsored by UNESCO and UNICEF. $10^{\text {th }} \mathrm{Jan}$. to $4^{\text {th }} \mathrm{Feb}$.

[9] Audu Andrew Jatau, International Letters of Social and Humanistic Sciences 8(1) (2014) $18-27$.

[10] Elizabeth Morenikeji Titilayo Adediran, Albert Oluyomi Kehinde, International Letters of Social and Humanistic Sciences 8(1) (2014) 66-75.

[11] S. A. Kazeem, K. Y. Balogun, International Letters of Social and Humanistic Sciences 8(2) (2014) 108-119.

[12] Godwin E. Itua, International Letters of Social and Humanistic Sciences 8(3) (2014) 200-207.

[13] Rowland U. Aleshi, Clementina N. Iloh, International Letters of Social and Humanistic Sciences 8(3) (2014) 208-216.

[14] Hannatu Abdullahi, International Letters of Social and Humanistic Sciences 8(3) (2014) 217-223. 
[15] Fowoyo Joseph Taiwo, International Letters of Social and Humanistic Sciences 8(3) (2014) 244-251.

[16] J. B. Babalola, Adesoji A. Oni, Ademola Atanda, International Letters of Social and Humanistic Sciences 10(2) (2014) 121-131.

[17] Prakash Chandra Jena, International Letters of Social and Humanistic Sciences 10(2) (2014) 91-99.

[18] Abubakar Aminu Boyi, International Letters of Social and Humanistic Sciences 3 (2014) 65-72. 